\title{
Assessing Sustainability of General Insurance Business through Real Time KPI using GPUs and Neural Networks
}

\author{
S.R.Pranav Sai, Phani Krishna Kandala, Satya Sai Mudigonda, Pallav Kumar Baruah
}

\begin{abstract}
Sustainability of a company is driven by its operational efficiency. The operational efficiency plays a significant role in a company's growth and profitability. Thus, it forms the foundation for the metrics of performance known as the Key Performance Indicators (KPIs). The KPIs establishes a connection between the concept of performance and the means to gauge the same. In this work, we use a neural network with two fully connected layers for analyzing and predicting the factors which are used for calculating the KPIs. The implementation was done with the help of a Graphics Processing Unit for running the complex calculations. The KPIs are obtained for the projected factors and the inference was done for five different non- life insurers in India, based on the public disclosure data available with insurance supervisors in India.
\end{abstract}

Keywords : Key Performance Indicators, Actuarial Analysis, Predictive Analytics, Fully Connected Neural Network, GPU

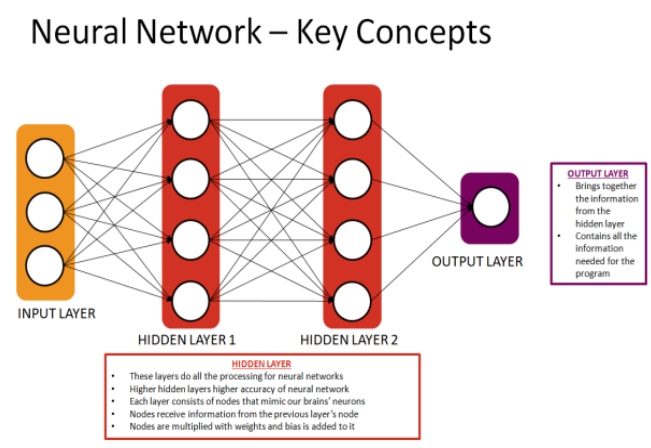

Figure 1: Neural Network Framework

Revised Manuscript Received on December 05, 2019

* Correspondence Author

S.R.Pranav Sai*, Doctorial Research Scholar, Department of Mathematics and Computer Science Sri Sathya Sai Institute of Higher Learning Puttaparthi, India,

Phani Krishna Kandala, Visiting faculty Sri Sathya Sai Institute of Higher Learning Puttaparthi, India,

Satya Sai Mudigonda, Senior Tech Actuarial Consultant, Hon. Professor in Department of Mathematics and Computer Science Sri Sathya Sai Institute of Higher Learning Puttaparthi, India,

Dr.Pallav Kumar Baruah, Associate Professor, Department of Mathematics and Computer Science Sri Sathya Sai Institute of Higher Learning, Puttaparthi, India

\section{INTRODUCTION}

Neural Networks is a programming algorithm which is biologically inspired, enabling the system to learn from the observational data. Thus, when a system learns the underlying data, it learns the patterns unseen to the human eye from the data. The data available are the ones which are disclosed by the insurance companies. These are quarterly data from the past can be fed into a neural network. This can analyze the trends in the data and can project these factors into the future. These factors lead to the calculation of the KPIs for the future time frame.

When managing operational efficiency, it is important to change over unique thoughts and subjective viewpoints of execution into those that can be measured scientifically. As we advance through the paper, we will perceive how this should be possible utilizing measurements called Key Performance Indicators (KPIs). KPIs measure the execution of a given procedure, which is being checked. There are distinctive KPIs, which screen an organization's presentation. They rely upon the line of business, topographical areas and numerous different components. In this work, we consider around 18 KPIs that have been alluded from (Shiu, 2004). These are comprehensively separated into two classes: three of which measure the presentation and the remaining 15 sway the exhibition of the organization at various degrees of activities. This builds up the connection between these two classifications of the KPIs and will empower us to really observe the effect of the exhibition of the organization with respect to every one of the KPIs considered. Here, the KPIs are measured for the projected factors, which are obtained by passing the expanded data into a fully connected neural network. Thus, the inferences are made by establishing the sensitivities of the obtained KPIs with regard to the performance of the company.Parallel computing has been done using GPUs. Generally,they are utilized in implanted frameworks, cell phones, PCs, workstations, and game consoles. Present day GPUs are exceptionally effective at controlling PC illustrations and picture handling. Since parallelism gives us efficiency on time and complexity, we have utilised the power of GPU in order to perform calculations. Thus, when these KPIs are projected for the future, inferences can be

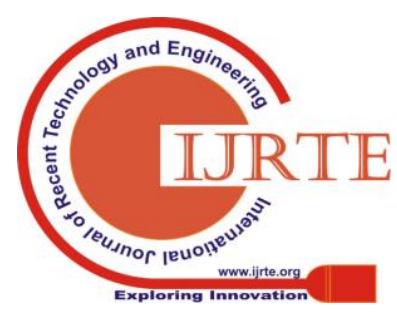


drawn with regard to how sustainable a company is. This work is divided into nine sections. Section 2 deals with the motivation behind this work and its benefits. Section 3 introduces the concepts of the Key Performance Indicators. Section 4 defines and categorises the various KPIs. Section 5 talks about the underlying data used for this work. Section 6 gives a four-step process of calculating the relevant KPIs and their sensitivities. Section 7 tabulates and gives insights for the results obtained. Section 8 talks about the limitation of the model used. Section 9 talks about the future steps to be taken from here.

\section{MOTIVATION}

Neural Networks are efficient algorithms which makes the machine learn the pattern from the underlying data. This is a faster and an effective way to analyze the features of a given data set. Once these are analyzed, they can be projected for the future for inferences to be made. Thus, they are a good means to project the KPIs of a company, insurance companies in specific. The insurance business goes about as a pad for each economy. It is accordingly significant for the business to work in a successful and effective way to guarantee the smooth running of the economy. In the developed economies, the GDP penetration of the insurance business is about $8 \%$ according to the reports of (Gonzalez, 2018). When we talk about the Indian protection industry, we are taking a gander at a structure of 59 insurance companies of which 24 are in the life business and 36 are associated with the non-life segment. These incorporate both open division and privately-owned businesses. India is a developing insurance on the planet, where in the infiltration of the Insurance segment as premiums make about $3.69 \%$ of the nation's GDP. The insurance business in India has seen a moderate yet an enduring development with time, from making about $2.71 \%$ of the GDP from premiums in 2001 to about $3.69 \%$ in the year 2017. The Indian insurance industry is relied upon to achieve a market of $\$ 280$ billion before the finish of the money related year 2020 (www.ibef.org). In such a situation, it is normal that the industry works at a highly efficient state of productivity to fulfill the needs of the economy. These structures the method of reasoning behind this work.

\section{KEY PERFORMANCE INDICATORS (KPIS)}

KPIs go about as a heart for each report in the process of decision making. They help measure the performance of destinations both quantitatively and subjectively. They structure reason for anticipating the patterns dependent on the present execution and the outer condition. They go about as markers as to an organization's performance inside a report. They can be discrete, continuous, categorical and many more, contingent upon the basic execution being checked. We screen an organization's performance in various fronts so as to improve the operational proficiency of the organization. The KPIs empower the organization to intently screen the regions where the performance needs to be improved.

\section{A. The Process of Obtaining the KPIs}

Firstly, list the fundamental activities of the business. Under every activity, recognize what are the means/stages included. For every one of these means, it is important to distinguish the different risks that can be present. Since we are focusing on execution enhancements, it is perfect that we manage just the downside risks. When we have the risks set up, we require a parameter that estimates the risk. This progression is vital as just risks that can be estimated can be managed utilizing actuarial or factual models. Having concocted the parameters, it is basic to check if the parameters are available in the open revelations of the organizations. In the event that a parameter is absent, at that point the data isn't open and consequently prompts trouble in removing data. Having the parameters set up, they can be assembled to frame the Key Performance Indicators. These decide the connection between an organization's activities and its performance. Presently, the KPIs we got will be of two general classes - ones acquired from the accepted procedures around and the ones got from the data available. They can likewise be put into the accompanying two classes: company specific variables and the economic variables. KPIs will frame the arrangement of informative factors for the factors that measure execution.

\section{KPI DEFINITION}

\section{A. Independent Variables}

The KPIs as mentioned earlier are those variables that have a direct impact on the company's performance. It is now necessary to describe what these KPIs are and what their relationship with the performance is.

\section{1) Unexpected Inflation (UI)}

Profits can be boosted with a small degree of inflation. The part of inflation which has not been considered into account which hampers the profits is known as unexpected inflation. Thus, this may result negatively on the performance of the company.

\section{2) Interest rate change (IRC)}

The valuation of assets and liabilities of an organization rely upon the loan fees winning in the economy and are touchy to little changes in that. Be that as it may, their effect on the presentation can't be legitimately caught as they rely upon length and convexity also. These are given by Reddington's immunization conditions.

\section{3) Interest rate level (IRL)}

The loan cost level here alludes to the security yields offered by the legislature for long haul securities which are sold in open market tasks directed by the national bank, if there should be an occurrence of India, Reserve Bank of India (RBI). The degree of loan fees in the economy has an effect on the speculation profit. Higher loan fees help the speculation returns of the organizations and henceforth have a positive effect on execution. 


\section{4) Equity Returns (ER)}

Equities or shares are a type of investment that give exceptional yields and capital increases yet are subject to market chance. This is because of the unpredictability of the benefits that render their forecast very troublesome. Organizations gain by this hazard by utilization of active investment strategies that digress from the benchmark file set by the administration. Consequently, plainly an expansion in the estimation of the values or offers influences execution decidedly. The value returns acquired can be estimated dependent on any of the stock trade information accessible.

\section{5) Company size (LOGTA)}

The general implication is that organizations that are greater perform better. Be that as it may, what is being enormous? Essentially the organization has more resources. More resources mean more wellsprings of salary. Also, more wellsprings of salary imply more noteworthy benefits which further means greater performance.

\section{6) Reinsurance dependence (RCTA)}

It is with regards to sharing or moving the risk that reinsurance comes into picture. Reinsurance can be taken as a treaty or a facultative coverage. The sort of reinsurance can be proportional or excess of loss basis or a combination. It can likewise have different layers. The nature and sort of reinsurance to be chosen relies upon the necessities of the insurer. Along these lines by deciding on reinsurance the backup plan can diminish his risk and work productively. Nonetheless, reinsurance likewise includes cost and this nibbles into the benefits of the organization. Henceforth as more risk is passed on to the reinsurer, it lessens the benefits and thus has a negative association with the performance.

\section{7) Leverage (TNTPSF)}

It is a typical practice in the insurance agencies to keep up a reserve for any conceivable future cases that may emerge. This training is known as reserving. Saves and arrangements are a part of the organization's benefit. Since the insurance agencies hold these funds, they should accommodate the policyholders in different structures, which come as limits offered in premiums. A case of this incorporates the No claims discount policy. An organization in this procedure must look to improve its capital structure or monetary influence which is the proportion of obligation to value. An organization's influence will positively affect the performance until it achieves its ideal capital structure and from that point it will see a downturn.

\section{8) Investments (TAISF)}

Investments incorporate those made in different government securities, debentures or bonds, other endorsed securities, and so forth. It is important to differentiate between investments and affiliated investments. Affiliated investments are those that are made in a backup of the organization. Along these lines, contingent upon whether the investments are affiliated or non-affiliated, the performance of the organization is influenced differently.

\section{9) Solvency margin (NANPW)}

Solvency is a proportion of how solvent an organization is. By solvent, we imply that an organization's benefits surpass its liabilities. The more noteworthy the edge, the more prominent is the capacity of the firm to meet its long-haul liabilities. Solvency is a marker of the money related quality of an organization. This clarifies the performance of an organization has an immediate relationship with the solvency.

\section{0) Stability of underwriting operation (ACGPW)}

Underwriting activities of a business decide the advancement of an organization and its improvement. In any case, it isn't generally the situation that an expansion in the guaranteeing tasks prompts more prominent business and the other way around. Truth be told, another factor that is intently connected with the guaranteeing activities of a business is the underwriting cycle. At the point when the underwriting cycle is evaluated delicate, the back up plans are prepared to acknowledge more business and thus the inclusion offered builds, which consequently pushes the premiums lower. At the point when the underwriting cycle is difficult, the case is actually the inverse, for example inclusion given by the insurers is lesser as they are as of now presented generally to the risk powers from the market. Thusly, the premiums charged heighten. Consequently, the connection between the security of the underwriting operation and the performance of the company can't strictly take one side.

\section{1) Liquidity (TLLA)}

While solvency talks about how solid a business is over the long haul, liquidity discusses the money related prosperity in the short run. When we state that an asset is liquid, it implies that it very well may be changed over to money promptly with just about zero expense. Examples include cash, bank balances, short term investments, shares, etc. An organization that is liquid will most likely meet its everyday commitments and consequently give a wonderful support of the two its providers and the clients. Thus, it is characteristic that it has a positive association with the performance.

\section{2) Stability of asset structure (CAM)}

Asset structure of an association is the dispersion of different classes of benefits that the association holds. Stability of this structure implies that there is no intense change in the asset structure year to year. Assume that there is a noteworthy change, it would mean less whenever credited to administrative change. Else, it tosses a warning about the organization's 
budgetary position. Hence, we would expect that a company's asset structure stability is directly linked to the increase in performance.

\section{3) Underwriting profits (UP)}

Underwriting benefits of an insurer allude to the benefits that emerge from the center business movement, for example premiums and claims. It is the distinction between the premiums got from different clients and the cases acquired alongside the costs associated with both the stages. High guaranteeing benefits of an organization suggest that the organization can deal with its risks proficiently. Also, this effectiveness is the thing that an organization looks for. Subsequently, there exists a positive connection between the organization's guaranteeing benefits and the performance.

\section{4) Insurer type (IT)}

An expert general insurer is a firm that offers protection spread for risks other than life. It is otherwise called property and casualty. It involves fire, marine, motor, travel, health and house protection and some more. A multi-line insurer is one who consolidates risks and offers items that oblige different needs. An example would be to bundle motor and health insurance under one product. The consolidated item costs lesser and is considerably more alluring. In any case, it makes the forecast of risk more complex. A composite firm is one that works in both the life and non-life territories. It has points of interest of strategically pitching general protection items to the policyholders previously having a life coverage contract. A reinsurer is an organization whose clients are insurance agencies. As referenced before, insurers sometimes take upon risks that they may want to share or transfer. The reinsurers aid the insurers in such a process. From perception of the performance of an organization, it isn't clear concerning whether a particular kind of backup plan has higher execution capacity than the others. Consequently, the association with execution is vague. This variable is estimated as a factor variable as it is a quality.

\section{B. The dependent variables}

Throughout the dialog in the past segment, we have gone over the relationship of the autonomous variable close by with execution, regardless of whether positive or negative. We have so far characterized what those factors are and how they sway execution. The inquiry presently emerges concerning what it implies when we state that an organization is performing great. How is the performance going to be estimated? In this segment, we characterize three factors that we will screen track execution.

\section{1) Percentage change in the shareholders' funds (PCSF)}

As a rule, an organization's performance is reflected in its share prices. Rising share prices are viewed as a positive execution measure for the organization. It likewise shows development. Thusly, by breaking down an organization's share price in the market, one can draw insights about how easily an organization is working. Be that as it may, the share prices of the organization likewise rely upon the interest and supply of the offers in the market. Henceforth, so as to get a progressively sensible interchange, an organization can utilize the investor's assets. This won't be swelled by elements that are not identified with an organization's performance.

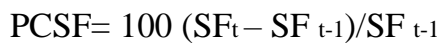

$\mathrm{SF}$ - Shareholders' fund at time $\mathrm{t}$

\section{2) Investment Yield (IY)}

Assume that we have contributed an aggregate of 1000 of a security. How could it be that we measure whether the security is performing great or not? Give us a chance to state following one year, its worth is 1100 . At that point, we can say that we have had an increase of 100 or an addition of $10 \%$ on the underlying sum. This rate increment in the estimation of the security is known as yield. This when connected to a heap of speculations is called as venture yield. Since insurance agencies put their salaries in different classes of advantages, the presentation of these benefits is an intermediary for the presentation of the organization. We measure the venture yield as pursues:

$\mathrm{IY}=100 * \mathrm{NII} /\left(0.5 *\left(\mathrm{TA}_{\mathrm{t}}+\mathrm{TAt}-1\right)\right)$

$\mathrm{NII}-$ Net Investment Income

$\mathrm{TAt}-$ Total assets at time $\mathrm{t}$

\section{3) Return on shareholder's funds (RSF)}

There is another approach to take a gander at the performance of an organization. Consider the above situation once more. Assume that we have sold the security following one year at a cost of '1300. At that point, we have earned a benefit of 300 on the security. This is the arrival gotten on the security. This can be estimated as a level of the underlying esteem. For this situation, return on the investor's assets is estimated as: $\mathrm{RSF}=100 * \mathrm{PBTD} /\left(0.5 *\left(\mathrm{SF}_{\mathrm{t}}+\mathrm{SF}_{\mathrm{t}-1}\right)\right)$

PBTD- Profits before tax and dividends

\section{DATA}

Each organization is ordered by IRDAI to own accessible their monetary expressions known as public disclosures. These are records that contain data in regard to the organization's performance and are utilized by various stakeholders and are accessible on (www.irdai.gov.in). The information contains 42 NL-schedules, few of which incorporate Profit/Loss account, Balance sheets, Premiums plan, Claims plan, Board of Directors plan, Geographic zones of activity, and so on. An organization must distribute all the 42 plans toward the finish of each quarter of a monetary year that ranges from first April to 31st March. This information for each organization, each quarter is accessible on the site of IRDAI. The data contained the various company specific factors. The factors are: 
Table 1: The List of Factors

\begin{tabular}{|c|c|}
\hline S.No & The Factors Derived \\
\hline 1 & Net investment income \\
\hline 2 & Total assets \\
\hline 3 & Shareholder's funds \\
\hline 4 & Profit before tax and dividends \\
\hline 5 & Reinsurance ceded \\
\hline 6 & Total net technical provisions \\
\hline 7 & Total affiliated investments \\
\hline 8 & Net assets \\
\hline 9 & Net premiums written \\
\hline 10 & Gross premiums written \\
\hline 11 & Total liabilities \\
\hline 12 & Liquid assets \\
\hline 13 & Property Cash \\
\hline 14 & Bonds \\
\hline 15 & Equities and other shares \\
\hline 16 & Affiliated investments \\
\hline 17 & Insurance debts \\
\hline 18 & Other assets \\
\hline 19 & Prepayments and accrued income \\
\hline 20 & Reinsurers' share of technical provisions \\
\hline 21 & Net premiums earned \\
\hline 22 & Net claims incurred \\
\hline 23 & Net operating expenses \\
\hline 24 & Adjustments for discounting \\
\hline 25 & Changes in technical provisions \\
\hline 26 & Increase in provision for unexpired risks \\
\hline 27 & Other technical income \\
\hline
\end{tabular}

\section{METHODOLOGY}

Firstly, the data was collected and cleaned. The following four steps were performed to the following data.

- Boot strapping to increase the number of data points

- Prediction using a fully connected neural network

- Calculating the KPIs

- Calculating the co-relation matrix

1) Boot strapping to increase the number of data points

Each of the above factors was available for every quarter in the period of observation. In this data, a data point is a quarter in a financial year with all the above factors in it. The data which were obtained had about 33 data points for each of the companies. In other words, 33 quarters' data were available. Since this data is relatively less, the method of boot strapping was used to expand this data. Thus, the number of data points increased to about 3300 data points after boot strapping.

\section{2) Prediction using a fully connected neural network}

The expanded data was then fed into a neural network with two fully connected layers. The first layer has fifty neurons and the second layer has twenty-five neurons. We used ReLU activation function for both the layers. Generally, individuals would in general utilize the logistic sigmoid or hyperbolic tangent as activation functions in hidden layers. The issue to a huge degree is that these saturate. During backpropagation, they may deliver an angle of zero for enormous information sources, which can moderate or even end the learning procedure. Incidentally, this is a better than average case of why it's imperative to get backpropagation and not regard it as a black box. The ReLU work $f(x)=\max (0, x)$ doesn't saturate for huge positive data sources. The gradient value of a ReLU activation is 0 or 1 always. This is as a conspicuous difference to numerous more seasoned activation functions which had subordinates in $[0,1]$. In a feedforward network, for instance, backpropagation applies the chain principle to process subordinates in prior layers dependent on subsidiaries in later layers by duplicating those individual subordinates together. A lot of subordinates somewhere in the range of 0 and 1 increased together wind up creating numbers considerably more like 0 - the alleged vanishing gradient problem. However, there was no activation function used in the output layer for the reason that we wanted the output values to be unrestricted. We ran the model for 1500 epochs. We used the Mean Squared error as our loss function. Ninety percent of the data available was used to train the network. The mean square error with projected and the test data turned out to be $5.35 \%$. Thus, this was network was used to analyse the trend and was used to predict the above-mentioned factors for next five years i.e., twenty quarters.

We used NVIDIA Tesla K40 GPU. It has got 2880 CUDA parallel processing cores. It supports 1024 threads per thread block. Each SM can support 16 thread blocks. We achieved hundred percent GPU utilisation.

\section{3) Calculating the KPIs}

The KPIs for each of the companies were calculated from the projected data. Thus, these give an overview of the expected performance of the company for the next twenty quarters.

\section{4) Calculating the co-relation matrix}

Once the KPIs were obtained, the co-relation matrix with respect to the dependent and the independent variables were obtained. This matrix gives the information about how sensitive each of the dependent variables is sensitive to each of the independent variables for each of the company.

\section{THE RESULTS}

Analysis was made for five different non- life insurers in India. The following are the graphs showing the trend of the various factors in the past and how they are projected in the future.

The $\mathrm{X}$-axis has the different quarters for which the data was obtained from the public disclosures. The $\mathrm{Y}$-axis is the amount in INR. The following KPIs were plotted for the five general insurers considered for the study, the KPIs plotted are

- Net investment income

- Total assets

- Shareholder's funds

- Profit before tax and dividends

- Reinsurance ceded 
- Total net technical provisions

- Total affiliated investments

- Net assets

- Net premiums written

- Gross premiums written

- Total liabilities

- Liquid assets

- Property Cash

- Bonds

- Equities and other shares

- Affiliated investments

- Insurance debts

- Other assets

- Prepayments and accrued income

- Reinsurers' share of technical provisions

- Net premiums earned

- Net claims incurred

- Net operating expenses

- Adjustments for discounting

- Changes in technical provisions

- Increase in provision for unexpired risks

- Other technical income

Thus, with the help of these graphs we can see how the past trends for each of the KPIs are reflected in the future by the model.

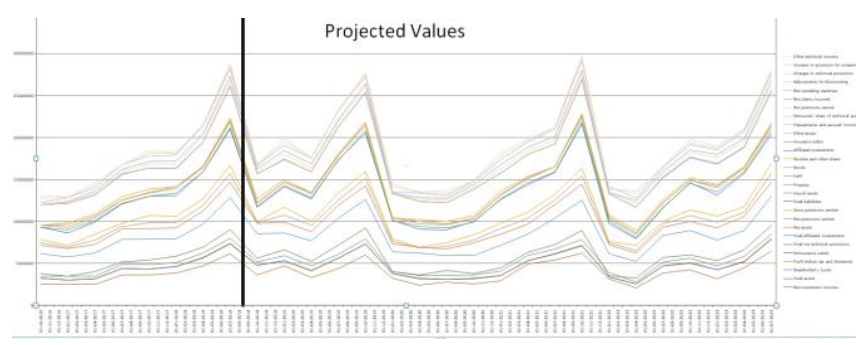

Figure 2: Insurer A

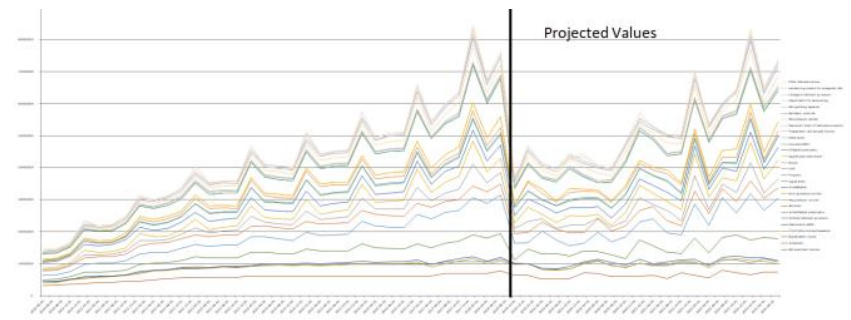

Figure 3: Insurer B

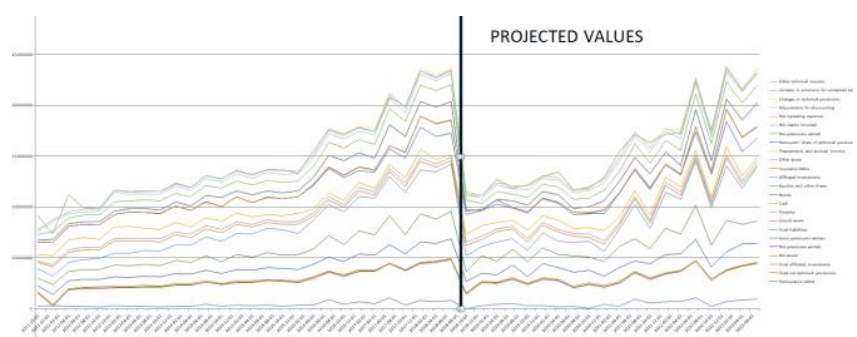

Figure 4: Insurer C

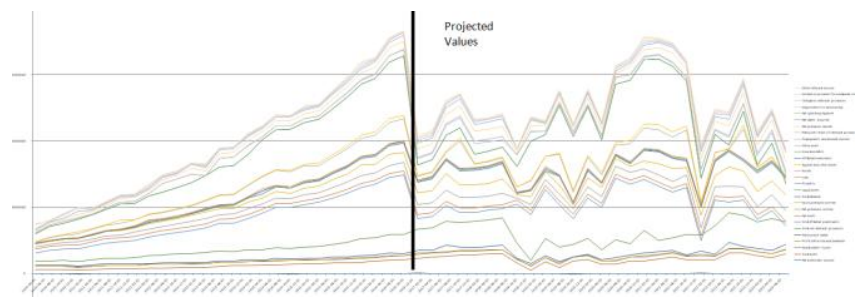

Figure 5: Insurer D

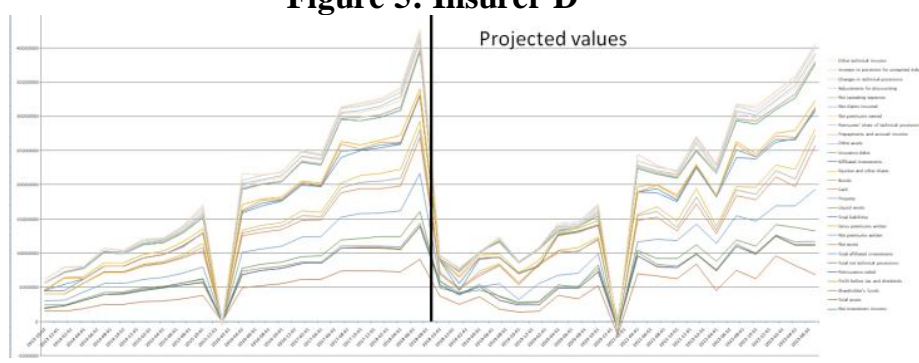

Figure 6: Insurer E

The following are the matrices which show how each of the dependent KPIs or the metrics, which directly reflect the performance of the company, sensitive to each of the independent KPIs.

Table 2: Insurer A

\begin{tabular}{|l|l|l|l|}
\hline INSURER A & IY & PCSF & RSF \\
\hline LOGTA & -0.5696 & 0.201568 & -0.27029 \\
\hline RCTA & 0.405549 & -0.27645 & 0.086372 \\
\hline TNTPCF & 0.293985 & 0.072624 & -0.36619 \\
\hline TAISF & -0.02254 & -0.51971 & 0.141529 \\
\hline NANPW & -0.12831 & -0.27378 & -0.19441 \\
\hline TLLA & -0.21507 & -0.17406 & -0.02617 \\
\hline UP & 0.134614 & 0.080786 & 0.070003 \\
\hline ACGPW & -0.22934 & 0.204276 & -0.02412 \\
\hline CAM & 0.04788 & 0.485979 & -0.49655 \\
\hline IY & 1 & 0.257554 & -0.08478 \\
\hline PCSF & 0.257554 & 1 & -0.19077 \\
\hline RSF & -0.08478 & -0.19077 & 1 \\
\hline UI & -0.16874 & -0.10355 & -0.03835 \\
\hline IRC & -0.16874 & -0.10355 & -0.03835 \\
\hline IRL & $-2.23 \mathrm{E}-17$ & $5.05 \mathrm{E}-17$ & $1.20 \mathrm{E}-16$ \\
\hline ER & 0 & $5.41 \mathrm{E}-17$ & $1.59 \mathrm{E}-16$ \\
\hline
\end{tabular}

The above table can be interpreted as follows: For the insurer A, the company size (LOGTA) affects the Investment Yield negatively and the degree with which LOGTA affects IY is by a factor of 56.96 percent. LOGTA positively affects the Percentage Change in the Shareholders' Fund by a factor of 20.16 percent. LOGTA affects the Return of the Shareholders' fund negatively by a factor of 27.03 percent. Thus, for insurer A, if the company size increases by one unit, IY will correspondingly decrease by .5696 units, PCSF will increase by .2016 units, RSF will decrease by .2703 units. Thus, depending on the weightage given to each of the dependent KPIs by an insurance company, the independent variables can be changed accordingly.

Table 3: Insurer B

\begin{tabular}{|l|l|l|l|}
\hline INSURER B & IY & PCSF & RSF \\
\hline LOGTA & $-0.46206 \mathrm{~h}$ & -0.08517 & -0.09394 \\
\hline
\end{tabular}


International Journal of Recent Technology and Engineering (IJRTE) ISSN: 2277-3878, Volume-8 Issue-4S2, December 2019

\begin{tabular}{|l|l|l|l|}
\hline RCTA & 0.10467 & 0.471816 & 0.1106 \\
\hline TNTPCF & -0.40944 & -0.21484 & -0.10882 \\
\hline TAISF & -0.50907 & -0.37441 & 0.063007 \\
\hline NANPW & 0.000597 & 0.332638 & -0.26322 \\
\hline TLLA & -0.45139 & -0.21468 & -0.47493 \\
\hline UP & 0.256141 & -0.03696 & 0.384475 \\
\hline ACGPW & 0.331408 & 0.012153 & 0.403534 \\
\hline CAM & -0.02617 & -0.22942 & -0.22812 \\
\hline IY & 1 & -0.02565 & 0.120048 \\
\hline PCSF & -0.02565 & 1 & -0.09609 \\
\hline RSF & 0.120048 & -0.09609 & 1 \\
\hline UI & 0.678108 & 0.015599 & 0.087001 \\
\hline IRC & 0.678108 & 0.015599 & 0.087001 \\
\hline IRL & $1.23 \mathrm{E}-16$ & 0 & 0 \\
\hline ER & $8.30 \mathrm{E}-17$ & $1.96 \mathrm{E}-17$ & $-1.69 \mathrm{E}-17$ \\
\hline
\end{tabular}

ER
\begin{tabular}{|l|l|l|l|}
\multicolumn{5}{|c|}{ Table 6: Insurer E } \\
\hline INSURER E & IY & PCSF & \multicolumn{1}{l|}{ RSF } \\
\hline LOGTA & -0.7497 & 0.193332 & 0.43247 \\
\hline RCTA & -0.46059 & 0.275886 & 0.2013 \\
\hline TNTPCF & -0.22866 & -0.13714 & 0.134643 \\
\hline TAISF & 0.032211 & -0.01989 & -0.28167 \\
\hline NANPW & 0.004779 & -0.07992 & -0.05783 \\
\hline TLLA & 0.123231 & 0.456865 & -0.31407 \\
\hline UP & 0.221641 & -0.67349 & 0.122572 \\
\hline ACGPW & 0.092432 & -0.51 & 0.466254 \\
\hline CAM & -0.09904 & -0.67686 & 0.236397 \\
\hline IY & 1 & 0.074066 & -0.54631 \\
\hline PCSF & 0.074066 & 1 & -0.41627 \\
\hline RSF & -0.54631 & -0.41627 & 1 \\
\hline UI & 0.429969 & -0.0587 & -0.44744 \\
\hline IRC & 0.429969 & -0.0587 & -0.44744 \\
\hline IRL & $-5.76 \mathrm{E}-17$ & $-1.96 \mathrm{E}-17$ & $3.76 \mathrm{E}-16$ \\
\hline ER & $-8.10 \mathrm{E}-17$ & $-1.18 \mathrm{E}-17$ & $3.46 \mathrm{E}-16$ \\
\hline
\end{tabular}

Now we derived the KPIs and their co-relations for the projected factors. We can make inferences on how these values affect the overall performance of the company by weighting the values according to the necessity, the stand affected and the environment around. This is necessary since there will be conflicts by the inferences of various values and the trend of the KPIs. We can make conclusions based on the following table.

Table 7: Determinants of performance

\begin{tabular}{|c|c|c|c|}
\hline No. & $\begin{array}{l}\text { Determinants } \\
\text { of } \\
\text { performance }\end{array}$ & $\begin{array}{l}\text { What stand } \\
\text { affected }\end{array}$ & $\begin{array}{l}\text { Relation with } \\
\text { performance }\end{array}$ \\
\hline 1 & $\begin{array}{l}\text { Unexpected } \\
\text { Inflation }\end{array}$ & $\begin{array}{l}\text { Claims, } \\
\text { Expenses, } \\
\text { Provisions } \\
\end{array}$ & Negative \\
\hline 2 & $\begin{array}{l}\text { Interest Rate } \\
\text { Change }\end{array}$ & $\begin{array}{l}\text { Assets, } \\
\text { Liabilities, } \\
\text { Claim Costs }\end{array}$ & $\begin{array}{l}\text { Depends on the } \\
\text { duration of the } \\
\text { assets and the } \\
\text { Liabilities }\end{array}$ \\
\hline 3 & $\begin{array}{l}\text { Interest rate } \\
\text { level }\end{array}$ & $\begin{array}{l}\text { Investment } \\
\text { Earnings }\end{array}$ & Positive \\
\hline 4 & Equity Returns & $\begin{array}{l}\text { Investment } \\
\text { Earnings }\end{array}$ & Positive \\
\hline 5 & $\begin{array}{l}\text { Underwriting } \\
\text { Cycle }\end{array}$ & $\begin{array}{l}\text { Underwriting } \\
\text { Profits }\end{array}$ & Intermediate \\
\hline 6 & Company Size & $\begin{array}{l}\text { Costs due to } \\
\text { economies of } \\
\text { scale }\end{array}$ & Positive \\
\hline 7 & $\begin{array}{l}\text { Reinsurance } \\
\text { Dependence }\end{array}$ & Profits & Negative \\
\hline 8 & Leverage & Equity & $\begin{array}{l}\text { Positive till the } \\
\text { optimum } \\
\text { capital } \\
\text { structure and } \\
\text { negative } \\
\text { thereafter }\end{array}$ \\
\hline 9 & $\begin{array}{l}\text { Affiliated } \\
\text { investments }\end{array}$ & $\begin{array}{l}\text { Insolvency risk } \\
\text { increases }\end{array}$ & Negative \\
\hline 10 & $\begin{array}{l}\text { Solvency } \\
\text { Margin }\end{array}$ & Reserves & Positive \\
\hline
\end{tabular}

For Insurer C there is no PCSF column. This is because, in the original data obtained from the public disclosures, the shareholders' funds remained constant for all the years for which the data is obtained. Thus, since SF is constant throughout, PCSF becomes zero for the same time period. Thus, PCSF column is not available for Insurer C.

Table 5: Insurer D

\begin{tabular}{|c|c|c|c|}
\hline INSURER D & IY & PCSF & RSF \\
\hline LOGTA & -0.20267 & 0.020826 & 0.232894 \\
\hline RCTA & 0.270777 & 0.055267 & 0.175741 \\
\hline TNTPCF & -0.06593 & -0.09076 & 0.193821 \\
\hline TAISF & 0.007927 & -0.24827 & -0.25906 \\
\hline NANPW & 0.065029 & 0.107394 & -0.08779 \\
\hline TLLA & -0.38342 & -0.07755 & 0.124419 \\
\hline UP & 0.184795 & -0.15548 & -0.20801 \\
\hline ACGPW & -0.05323 & -0.21986 & -0.1165 \\
\hline CAM & -0.17254 & 0.360383 & -0.16479 \\
\hline IY & 1 & 0.280637 & 0.637147 \\
\hline PCSF & 0.280637 & 1 & 0.025576 \\
\hline RSF & 0.637147 & 0.025576 & 1 \\
\hline UI & 0.056915 & -0.06337 & -0.23679 \\
\hline IRC & 0.056915 & -0.06337 & -0.23679 \\
\hline IRL & $8.34 \mathrm{E}-17$ & $2.81 \mathrm{E}-17$ & $-5.50 \mathrm{E}-17$ \\
\hline
\end{tabular}

Margin 


\begin{tabular}{|l|l|l|l|}
\hline 11 & $\begin{array}{l}\text { Stability of } \\
\text { underwriting } \\
\text { operations }\end{array}$ & Premium rates & $\begin{array}{l}\text { No prior } \\
\text { expectations }\end{array}$ \\
\hline 12 & Liquidity & Investments & Positive \\
\hline 13 & $\begin{array}{l}\text { Stability of } \\
\text { asset } \\
\text { structure }\end{array}$ & Assets & Positive \\
\hline 14 & $\begin{array}{l}\text { Underwriting } \\
\text { Profits }\end{array}$ & Profits & Positive \\
\hline 15 & Insurer Type & Business Mix & Indeterminate \\
\hline
\end{tabular}

Thus, for the KPIs for the projected data, we can see the expected performance of the company and can get a bigger, better and a quantitative perspective of the companies studied.

\section{VIII.LIMITAIONS OF THE MODEL}

The data available is sparse. The maximum number of data points which were available for a company was 33. Thus, the data had to be expanded in order to train the neural network better. Thus, when boot strapping was done, the trends of all the factors were lost. Thus, the data which was fed to the neural network didn't have the original trend. Though the neural network found the pattern and projected the factors (the mean square error between the projected and the test data was about five percent), the continuity between the original data and the projected data was not very evident. Company specific factors could be projected using the

past data. But, the factors like the returns of the ten-year government bonds, equity index, inflation rates and the tax rates were not predicted. Since there are involved models to predict them and it may not make sense to predict these factors for a period of 5 years because of the volatility of the external environment. Thus, where necessary, they were assumed to be constant for the projected. There are several other factors that determine the performance of the company apart from the once mentioned above. It may not be always necessary to use the one-sizefits-all approach. These factors can also be tailor made for the companies in specific.

\section{NEXT STEPS}

In this work, the problem of predicting these factors was mapped to a regression problem. The data we have is a temporal data. That is, the value of the data points is actually affected by the past values, and these points will affect the future values. In this work, the prediction of the factors was dealt individually. This can be enhanced by finding out the features i.e., the factors on which the chosen factor depends on. This will give a better credibility to our estimated value. Thus, a Recurrent Neural Network (RNN) can be used for capturing these as part of the future work. The current work is based on the data of five non-life insurance companies. In the future work is planned on including data from all the insurance companies and create a automated framework for making future predictions. We also plan on extending this work to other Lines of Business such as health, life and pensions.

\section{ACKNOWLEDGMENT}

We acknowledge Harold D Singh(FSA), Ajay Singh (M.Tech), Manoj Kumar Reddy (M.Tech) and Sai Praneeth
(M.Sc Actuarial) for their valuable inputs. We express our deep sense of gratitude to Sri Sathya Sai Institute of Higher Learning (Deemed to be University) SSSIHL - for providing IT expertise, IT Labs, Previous publications and Actuarial consultants for this research work.

\section{REFERENCES}

1. Pradyumna M, Pranav Sai S.R.- A Framework for assessing performance sensitivity of select KPIs for General Insurance companies in India using Risk Management Dashboard Approach , IJSER,Volume 10, Issue 3, March 2019 Edition

2. Shiu, Y. (2004). Determinants of United Kingdom General Insurance Company Performance. British Actuarial Journal. 10. $10.1017 /$ S 1357321700002968.

3. https://www.ibef.org. (n.d.). Retrieved https://www.ibef.org/industry/insurancesector-india.aspx

4. www.irdai.gov.in. (n.d.). Retrieved from https://www.irdai.gov.in/ADMINCMS/cms/NormalData_Layout.aspx?p age $=$ PageNo765\&m id=31.2

5. Badi H. Baltagi ,Econometric Analysis of Panel Data ,Fifith edition , Sepetember 2013, ISBN: 978-1-118-67232-7, John Wiley \&. Sons, Ltd Copyright (C) 2005 John Wiley \& Sons Ltd, The Atrium, Southern Gate, Chichester, West Sussex P019 8SQ, England

6. Booth, P., Chadburn, R., Cooper, D., Haberman, S. \& James, D., Modern actuarial theory and practice, second edition , september 2004, ISBN-13: 978-1584883685, Chapman \& Hall, U.K.McGraw-Hill, U.K.

7. Browne, Mark J., and Robert E. Hoyt. "Economic and Market Predictors of Insolvencies in the Property-Liability Insurance Industry." The Journal of Risk and Insurance, vol. 62, no. 2, 1995, pp. 309-327. JSTOR, www.jstor.org/stable/253794.

8. Canadian Institute of Actuaries (1998). Standard of practice on dynamic capital adequacytesting (in effect January 1, 1999). This document is available at http://www.actuaries.ca/publications/sop___e.html

9. Blum, Peter, and Michel Dacorogna. "DFA-Dynamic Financial Analysis." Wiley StatsRef: Statistics Reference Online (2014).

10. Enz, R. \& Karl, K. (2001). Profitability of the non-life insurance industry: it's back-tobasics time. Swiss Re. Sigma, 5, 1-37.

11. Greene, William H. Econometric analysis.2003,ISBN 13 9780130132970. Pearson Education India

12. Gujarati, Damodar N., Basic econometrics, third edition, 1995, ISBN 0-07-025214-9, New York: McGraw-Hill.

13. Neter, J., Wasserman, W. and Kutner, M.H. (1989) Applied Linear Regression Models. 2nd Edition, Richard D. Irwin, Inc., Homewood

14. Pesaran, H., Smith, R. \& Im, K. (1996). Dynamic linear models for heterogeneous panels. In the econometrics of panel data. Edited by Ma“" tya s, L. \& Sevestre, P. (second revisededition). Kluwer Academic Publishers, The Netherlands.

15. https://www.irdai.gov.in/ADMINCMS/cms/NormalData_Layout.aspx?p age=PageNo129\&mid=3.1.9

16. Gonzalez, R. (2018, July). A work in progress. The Actuary, The magazine of the Institute and Faculty of Actuaries , pp. 23-25

17. https://www.irdai.gov.in/ADMINCMS/cms/NormalData_Layout.aspx?p age $=$ PageNo264\&mid $=3.2 .10$

18. Schmidhuber, Jürgen. "Deep learning in neural networks: An overview." Neural networks 61 (2015): 85-117.

19. Glorot, Xavier, and Yoshua Bengio. "Understanding the difficulty of training deep feedforward neural networks." Proceedings of the thirteenth international conference on artificial intelligence and statistics. 2010.

20. Ilya Sutskever, Oriol Vinyals, Quoc V. Le , Sequence to Sequence Learning with Neural Networks, (Submitted on 10 Sep 2014 (v1), last revised 14 Dec 2014 (this version, v3))

21. Bergstra, James, et al. "Theano: Deep learning on gpus with python." NIPS 2011, BigLearning Workshop, Granada, Spain. Vol. 3. Microtome Publishing., 2011.

22. W. Keckler, Stephen \& Dally, William \& Khailany, Brucek \& Garland, Michael \& Glasco, David. (2011). GPUs and the Future of Parallel Computing. Micro, IEEE. 31. 7 - 17. 10.1109/MM.2011.89.

23. Warburton, Kevin. "Deep learning and education for sustainability." International Journal of Sustainability in Higher Education 4.1 (2003) 44-56.

24. Seiya Tokui, Kenta Oono, Shohei Hido, Justin Clayton. Chainer: a Next-Generation Open Source Framework for Deep Learning. In Workshop on Machine Learning Systems at Neural Information Processing Systems (NIPS), 2015 
25. Alec Radford \& Luke Metz indico Research Boston, MA

\{alec,luke\}@indico.io, Soumith Chintala Facebook AI Research New York, NY soumith@fb.com UNSUPERVISED REPRESENTATION LEARNING WITH DEEP CONVOLUTIONAL GENERATIVE ADVERSARIAL NETWORKS

\section{AUTHORS PROFILE}

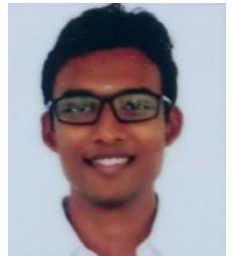

S.R.Pranav Sai - He is a doctoral research scholar in Sri Sathya Sai Institute of Higher Learning in the field of Actuarial sciences. His area of research includes Enterprise Risk Management, Operational Efficiency of insurance companies and IFRS 17. He is an Actuarial data science expert and has published research papers in international journals.

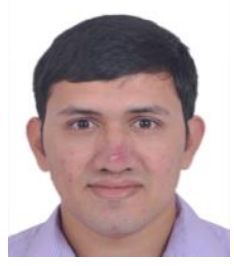

Phani Krishna Kandala - He is Assistant Vice-President in a leading Re-Insurance company. He is an active researcher in the field of actuarial data science. He has completed his Masters degree in mathematics and has done his M.Tech. in computer science. He has published several research papers and has presented in various national and international conferences

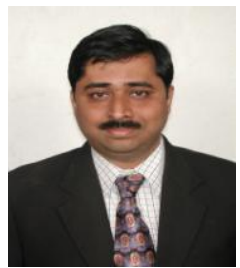

Satya Sai Mudigonda - A Senior Tech Actuaria Consultant providing services in USA and India. With a wide skill set, he managed numerous multi-million-dollar international assignments for major insurance companies across the globe. He is an honorary professor in Sri Sathya Sai Institute of Higher Learning. He has published about fifteen papers in the field of Actuarial data science and has presented in several international conferences.

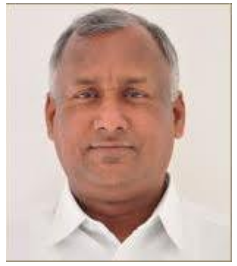

Dr. Pallav Kumar Baruah - $\mathrm{He}$ is an Associate Professor and the former HOD of the Department of Mathematics and Computer Science of Sri Sathya Sai Institute of Higher Learning. He has guided several research scholars in mathematics and computer science. He has numerous research publications to his credit and has presented in several national and international conferences. 